\title{
Paid Parental Leave and Female Labour Supply: A Review
}

\author{
Guyonne Kalb* \\ Melbourne Institute of Applied Economic and Social Research, \\ University of Melbourne, VIC 3010 Melbourne, Australia; ARC Centre of \\ Excellence for Children and Families over the Life Course; and IZA (Bonn)
}

August 2017

\begin{abstract}
This review is based on the international and Australian literature on paid parental leave. It does not aim to be exhaustive but focusses on the impact paid parental leave has on the labour force participation of mothers in developed countries. Four aspects of paid parental leave are explored, including the impacts of: introducing paid parental leave, changing the duration of existing paid parental leave, changing the generosity of existing paid parental leave payments, and paid paternity leave. It interprets the implications in the context of Australia, and includes descriptive information on the recent and current situation in Australia.
\end{abstract}

Keywords: labour supply, parental leave, mothers

JEL: J13, J18, J22

\section{Acknowledgements}

This article draws on joint work and has benefitted from discussions with Barbara Broadway, Belinda Hewitt, Daniel Kuehnle, Bill Martin, Duncan McVicar, Abigail Payne and Thor Thoresen. The comments and suggestions of two anonymous referees are gratefully acknowledged. The views expressed in this article and any remaining errors are those of the author alone.

* Address details: Melbourne Institute of Applied Economic and Social Research; Level 5, FBE Building, 111 Barry Street; University of Melbourne; VIC 3010; Australia; e-mail: g.kalb@unimelb.edu.au; phone: +61 38344 2095; fax: +61 383442111. 


\section{Introduction}

Australia has been quite hesitant in introducing a universal paid parental leave scheme. For many years it has been one of the few developed countries (together with the US) which did not provide universal paid leave to new parents. The Human Rights and Equal Opportunity Commission (HREOC) proposal for paid parental leave (HREOC 2002) was ignored in the early 2000s, with the then Government introducing a general maternity payment which was not linked to workforce participation, and initially not income tested. ${ }^{1}$ Australia had to wait until the Productivity Commission report in 2009, with the policy recommended in this report nearly completely adopted from 1 January 2011. The new policy filled a need identified in earlier studies. Based on a survey held in 2005, Whitehouse et al. (2008) report that financial need and limited access to paid maternity leave were the most common reasons for returning 'early' from maternity leave. They conclude that improved availability of paid leave is more likely to be welcomed than further extension of (unpaid) leave duration. This view was supported by results in Edwards (2006) which suggest that Australian women of childbearing ages were willing to accept lower wages for jobs offering eligibility for paid maternity leave.

Deven and Moss (2002) compare a number of European countries as well as Australia, Canada, New Zealand and the US. They note the marked lack of formal paid leave entitlements in Australia, New Zealand and the US at the time. They remark that these English-speaking countries and the UK and Ireland have relatively weak leave policies in common, and suggest this may be related to these countries having liberal welfare states. In the liberal welfare state context, statutory leave policies may be seen as interference in the market, threatening economic deregulation and labour force flexibility. In this view of the world, support for working parents should arise from individual negotiation or collective bargaining and be in line with the labour force needs of the employer.

Discussion in articles by Ainsworth and Cutcher (2008) and Baird (2003, 2004) also try to explain what the underlying reasons may be for Australia's hesitation to provide paid parental leave. Ainsworth and Cutcher carry out a qualitative analysis of three newspaper articles from 2004 representing typical examples of the public discourse on gender, parenthood and work. They argue (on p. 388) that "Australian women have been constructed as nation builders with a primary role as maternal citizens.” with men being absent (at work or at war), and women

\footnotetext{
${ }^{1}$ From 1 January 2009 the then so-called Baby Bonus (formerly Maternity Allowance) remained available to families with household income under $\$ 150,000$ only.
} 
receiving social welfare for having children rather than support to return to work from Government. Baird (2003) examines paid maternity leave in the context of Australia's industrial relations framework, since in line with the liberal welfare state argument by Deven and Moss, the Government at the time argued that paid maternity leave, being a condition of work, should be negotiated through that framework rather than prescribed by Government. Although annual leave and sick leave were generally accepted and included as paid leave in the federal award system, Baird reports that only a few federal awards also included paid maternity/parental leave (e.g. for Commonwealth public servants). ${ }^{2}$ Neither was enterprise bargaining particularly useful in gaining paid maternity leave, and few improvements had been achieved through the avenue of company policy. As a result, paid maternity leave remained available to a small group of women only. Baird attributes the fact that paid maternity leave has not been treated as an essential work entitlement within the industrial relations system due to the focus on male wage earners and their needs. Within the social welfare system, the focus has been on providing for all mothers rather than addressing the needs of women in employment specifically. In a subsequent paper, Baird (2004) interprets the lack of positive outcomes with regard to paid parental leave in light of the then existing orientations towards the debate. She identifies the welfare orientation, the bargaining orientation and the business orientation. However, an equity orientation which explicitly recognises women's (and men's) multiple roles (in the family and in the workplace) was missing. In the current debate the welfare orientation (as reflected in the proposed changes to the paid parental leave which would discourage employers from supplementing the government-provided scheme) appears dominant within Government.

Although availability of family-friendly policies is very important and is the first step towards facilitating parents to combine family and work, perhaps equally important is acceptance of these policies by managers and co-workers. This is highlighted in a case study by Diamond et al. (2007), who discuss the differences in the ease of access to paid leave (combined with other leave) and part-time work (after returning from leave) in a large organisation. Especially in male-dominated sections of this organisation, knowledge and acceptance of relevant organisational policies was limited, which meant women needed to do their own research and "fight" to access the arrangements they were entitled to.

\footnotetext{
${ }^{2}$ The HREOC proposal (2002: p.30) mentions "A review of 100 federal awards with the highest coverage of workers, undertaken by the then Commonwealth Department of Employment, Workplace Relations and Small Business found that only six federal awards included provision for paid parental leave.”
} 
The aim of this article is to review the literature related to the effect of paid parental leave schemes on female labour supply. We provide a literature review examining paid parental leave from four different angles. First, studies are discussed that have investigated the impact of introducing paid parental leave. Second, the focus is on the impact of changing the duration of existing paid parental leave; third, the impacts of changes in the generosity of existing paid parental leave payments are reviewed; and fourth, the impact of paternity leave is reviewed.

The review's focus on female employment outcomes does not imply that the impact of paid parental leave on mother's physical and mental health, or on the child's health and development is of any lesser importance. In fact, when deciding on the desirability of a paid parental leave system, all these aspects should be taken into account together. The narrow focus of this review serves to keep the task manageable. However, separate reviews focussing on health outcomes or on child outcomes would also be very useful, and would complement this review. Similarly, when examining female labour force participation, paid parental leave is evidently not the only relevant policy. Deven and Moss (2002) mention the Council of Ministers Recommendation on Child Care of 1992, which was adopted by all EU member states and identified four areas needed to enable women and men to reconcile employment and family responsibilities. Leave was mentioned alongside childcare services, the workplace environment, and greater sharing of caring responsibilities between men and women. However, our focus is mainly on paid parental leave.

In several papers a distinction is made between maternity leave and parental leave, since many countries provide a period of maternity leave (of around 2 to 3 months) to be taken by the mother (sometimes mandatory) separately from parental leave (Deven and Moss, 2002). This is done to promote/protect mother and child health and well-being. Australia does not have designated maternity leave, so we treat maternity leave and parental leave as interchangeable, and add maternity leave to parental leave to compare total leave available to mothers/parents across countries.

To complement the literature review, statistics on female labour supply, and mothers' labour supply specifically, are first presented in this article to provide a context to the discussion in later sections. In addition, an overview is given of the varying schemes around the world, describing: when they were introduced, how they are financed, the length of paid leave provided and the generosity of paid leave in terms of the level of payments provided. 
This article is structured as follows. Section II provides an overview of female labour force participation, in particular that of (young) mothers in Australia, and compares this with female labour force participation in a number of other countries. This is followed in Section III by an overview of the different paid parental leave payments across the world, in particular those in developed countries. The next four sections discuss the literature on paid parental leave and its impact on female labour supply: the introduction of paid parental leave in Section IV, changes in the length of paid parental leave in Section V, and changes in the payment level of leave in Section VI. The literature on paid paternity leave and its impact on mothers is briefly discussed in Section VII. A discussion of some implications for Australia in Section VIII concludes the article.

\section{Female labour force participation in Australia}

\section{II.1 Trends}

Over the past few decades, female labour force participation has increased substantially, as can be seen in Figure 1. The employment rate increased from 40 percent in 1978 to over 55 percent in August 2016, with corresponding labour force participation rates just under 5 percentage points higher over this period, indicating an unemployment rate of under 5 percent. The figure shows clearly that amongst working women the proportion employed in a part-time job has been steadily increasing from just under 34 percent to just under 47 percent, nearly half of all employment.

This increase amongst women in general also occurred amongst mothers as can be seen in Figure 2, which focusses on mothers (and fathers) distinguishing between parents of preschool children (0-5 years old) and school-aged children (6-14 years old). There are substantial differences by the age of the youngest child. Labour force participation rates of mothers of preschool children have increased substantially (7.0 percentage points) over the eight years reported in the figure, whereas participation of mothers of school-aged children has remained fairly stable at a much higher level. Compared to many other countries across the world, labour force participation and hours worked by mothers of preschool children are particularly low, whereas for women without children, labour force participation and hours worked are high, and at a similar level to countries with high female labour force participation such as Norway (Kalb and Thoresen, 2010). 
Figure 1 Female labour force participation and part-time vs full-time hours between February 1978 and August 2016 (monthly data, population aged 15 and over)

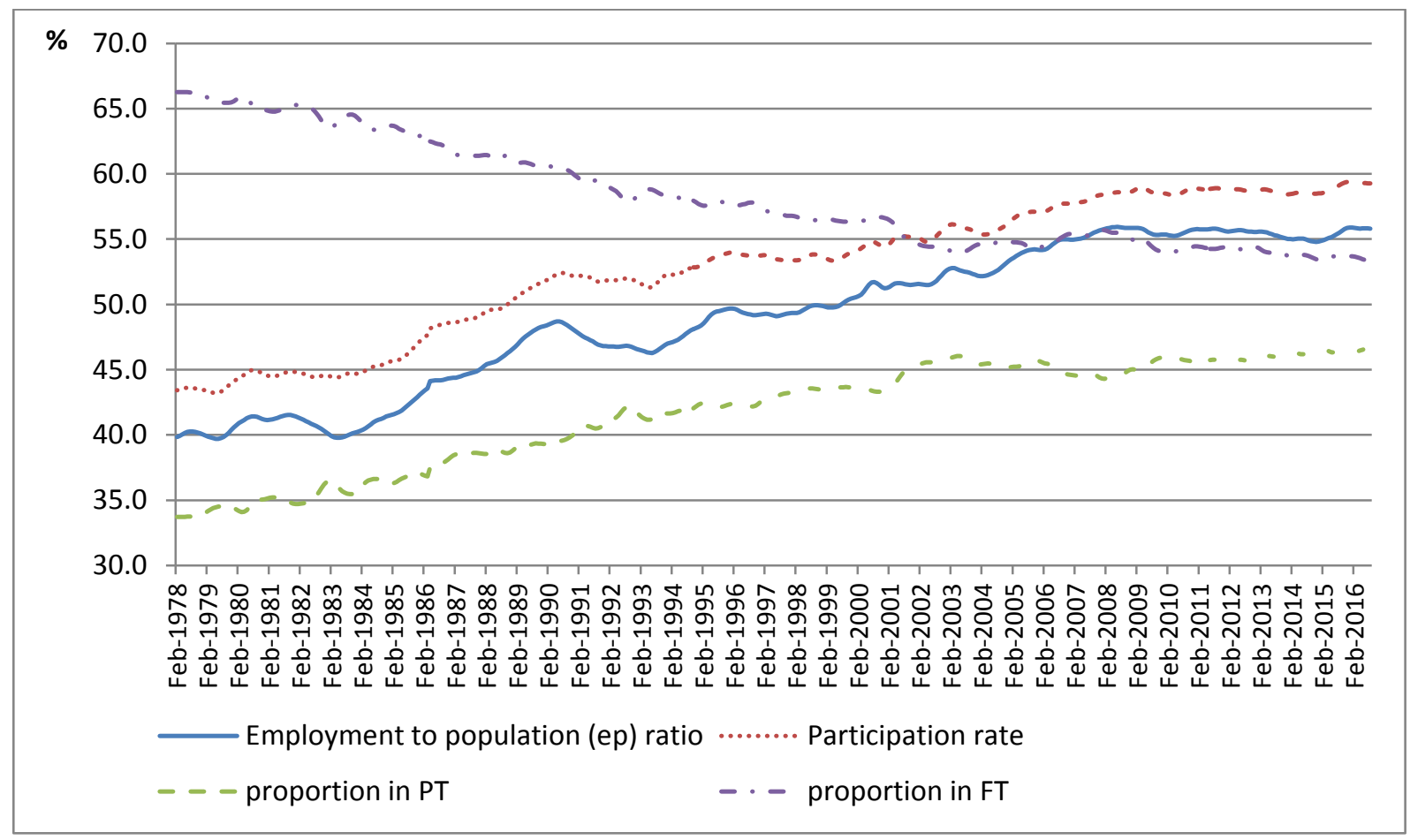

Source: Trend numbers from the Labour Force, Australia, Australian Bureau of Statistics (ABS) catalogue number 6202.0

Figure 2 also suggests that from 2011 onwards, labour force participation of mothers of preschool children has been slowly but steadily increasing, whereas before 2011 the trend appears quite flat. Although the changes for men are quite small, there is some indication of an increase in the proportion out of the labour force, particularly for fathers of school-aged children. At the same time the proportion of men working part time has been increasing for fathers of preschool and school-aged children, while for women this proportion has slightly decreased. It will be interesting to observe whether this development continues into the future and whether it is due to fathers taking on more responsibilities in the care for their children. 
Figure 2 Labour market status for men and women (aged 20 to 74) by age of youngest child between 2006-07 and 2014-15

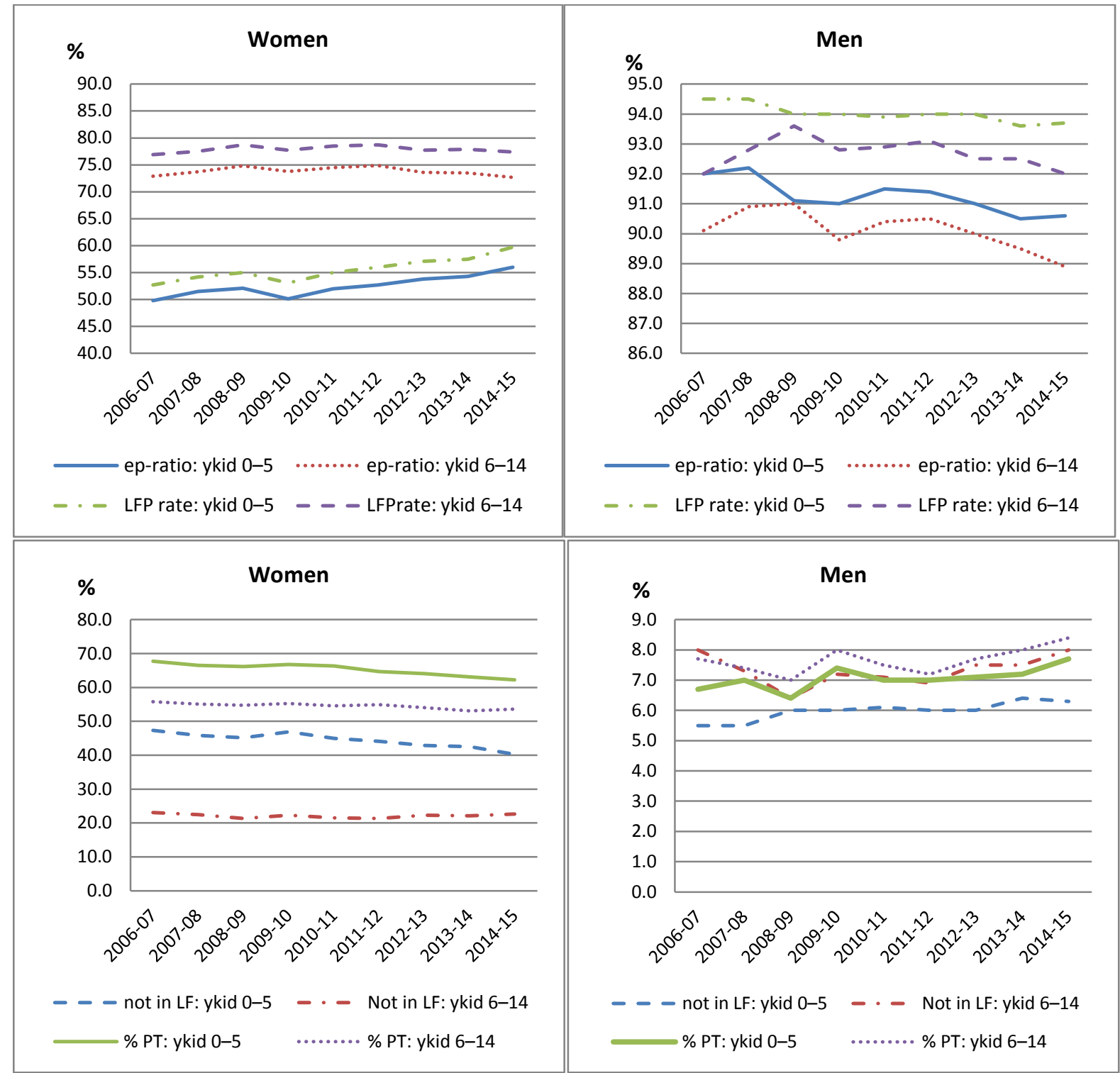

Source: Gender Indicators, Australia, February 2016, ABS catalogue 4125.0.

\section{II.2 Comparison to other countries}

As mentioned in the previous section, the labour force participation and employment rate of Australian mothers lags behind that of mothers in other countries. Figure 3 shows that in 2014, Australia is ranked below the average of the 31 OECD countries included in the graph, and is ranked about one third from the back. Compared to Sweden which has the highest employment rate, Australia’s employment rate is just over 20 percentage points lower. 
Figure 3 Maternal employment rates, 2014 or latest available year ${ }^{\mathrm{a}}$

(Employment rates (\%) for women (15-64 year olds ${ }^{b}$ ) with at least one child aged 0-14 )

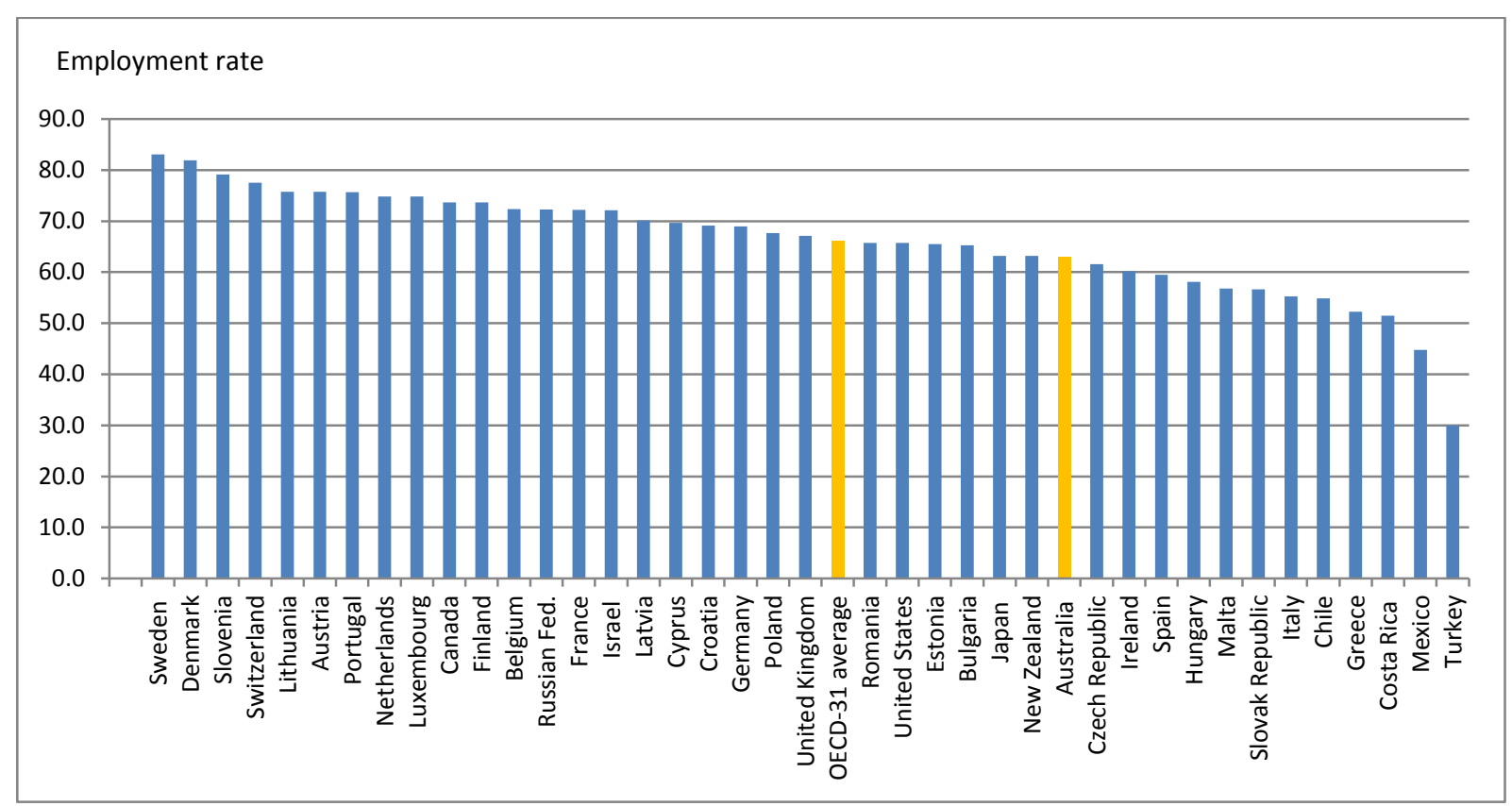

Notes: a) Data for Denmark and Finland is from 2012, and for Chile, Germany, and Turkey from 2013.

b) For Japan, all ages, and for Sweden women aged 15-74 are included.

c) For Canada children aged 0-15, for Sweden children aged 0-18, and for the United States children aged 0-17 are included.

Source: OECD database (see http://www.oecd.org/els/family/database.htm).

One main difference with other developed countries is that until recently Australia had no universal paid parental leave scheme. The question is to what extent this could play a role in mothers' short and medium labour supply decisions. Obviously, there are several other important factors that play a role, such as affordable and high-quality childcare that is readily available $^{3}$, but the first few months after childbirth often are a difficult period in juggling family needs and work responsibilities. It seems plausible that when faced with a lack of flexibility, mothers may withdraw from the labour force at this time which may have longterm consequences for these women. This is discussed in later sections of this article, but first we examine the availability of family-friendly policies more generally.

Figure 4 presents an overview of public expenditures (in 2011) on childcare support and on preschool education. It is clear that the Nordic countries have a strong focus on providing childcare which is not matched by any of the other countries. This seems to translate in high employment rates in Figure 3, but some of the low childcare spenders, such as Switzerland or the Netherlands, also perform reasonably well with regard to the level of employment

\footnotetext{
${ }^{3}$ For example, Renda et al. (2009) report that good childcare policies (especially in terms of affordability) are most often mentioned as a work-family policy that would have been useful to them after their child was born.
} 
amongst mothers. Expenditure on pre-primary education can also facilitate to some extent parents' labour force participation, but this is usually only provided to children from 3 or 4 years of age onwards which may be too late to prevent human capital loss and preserve a strong connection to the labour market.

Figure 4 Public expenditure on childcare and pre-school, per child, 2011

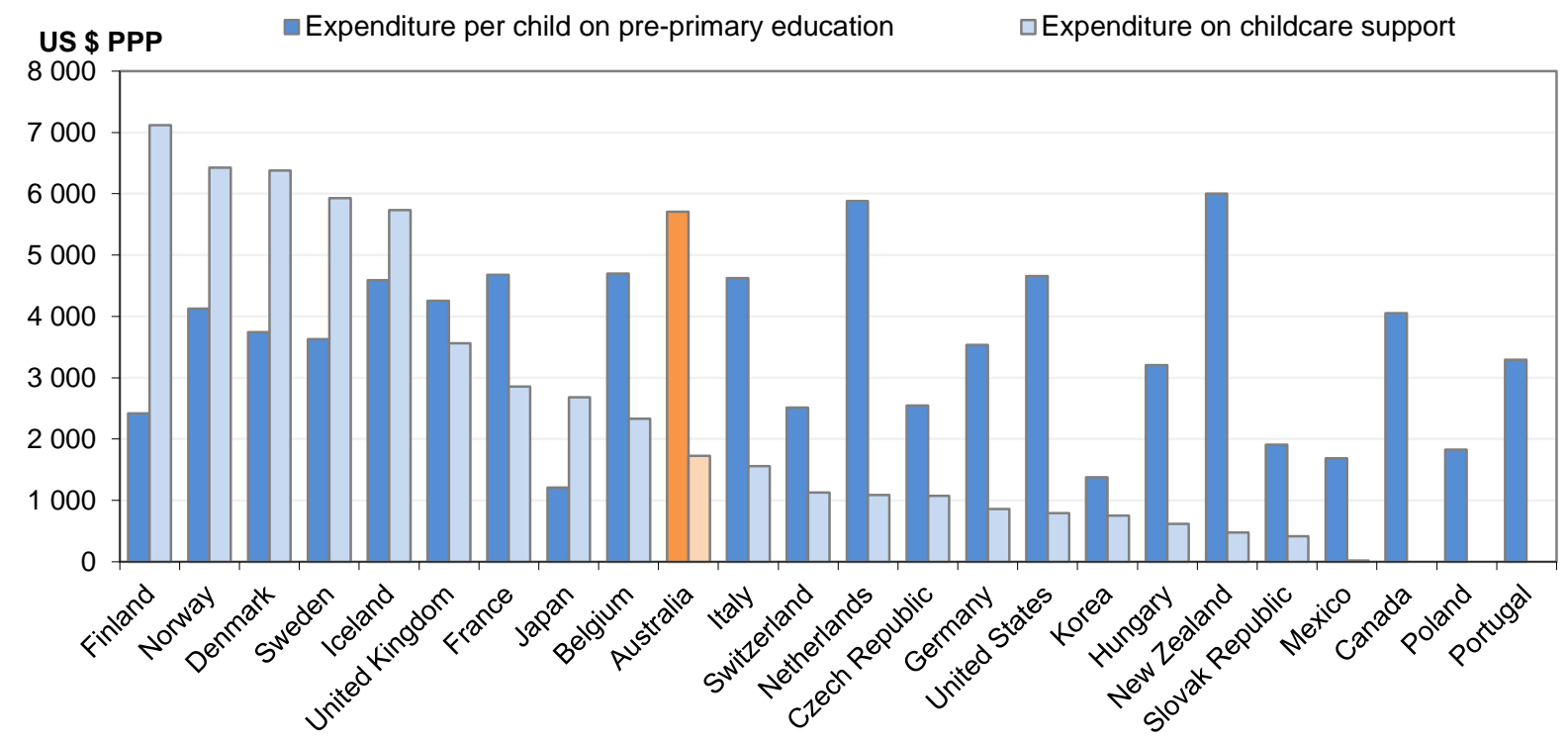

Source: Social Expenditure database 2013; OECD Education database; Eurostat for Non-OECD countries.

The existence of a possible link between high expenditures on childcare (and other family policies) and female employment outcomes is supported by multivariate analysis in Datta Gupta et al. (2008) who point to the positive impact that family policies (including generous leave schemes and subsidised access to childcare) in the Nordic countries have had on female labour supply, fertility and children's development. However, there is a downside (aside from the expense), especially for highly educated women who may be faced by a "system-based glass ceiling” (Datta Gupta et al., 2008: p.85). This issue (see also Hegewisch and Gornick, 2011:130-132) may arise from family policies being mostly directed to (and taken up by) mothers who may self-select into certain types of jobs (with lower pay but good family policies) or who may be discriminated against by employers (with this effect potentially extending to women without children). A possible solution may be family policies aimed at a more equal division of caring time by both parents. However as a number of studies show, this is not straightforward. The introduction in Sweden of one month of parental leave that could only be taken by the father had no noticeable effects on medium-term outcomes such as doing a larger share of caring work, or improving mothers' employment or wage outcomes 
(Ekberg et al., 2013). The only visible effect was that it increased the leave-taking in the first year after birth.

In countries where paid parental leave is universal and is used by nearly all mothers, an unintended consequence of generous parental leave policies may be that the impact of family formation on women's labour market outcomes even goes beyond the direct effects on women choosing to become mothers and extend to all women as employers may anticipate that women will have children and take paid leave. Datta Gupta and Smith (2002) analyse the family gap in wages for women in Denmark. The effect of having a child on a mother's availability for the labour market is temporary and seems to reflect a temporary pause in human capital accumulation. Although there may be many other explanations of the gender wage gap, the analyses in this study cannot reject the hypothesis that the effect of potential children, career interruptions, etc., influences the wage level of all women through statistical discrimination, instead of applying only to those who become mothers; e.g. women's starting salaries are lower than men's on average.

Blau and Kahn (2013) discuss the balancing act that may be required when introducing family policies. Their analyses indicate the importance of family-friendly policies such as parental leave and working hours flexibility in maintaining high female labour force participation, explaining over a quarter of the decrease in US female labour force participation relative to other countries. However, on the upside for the US, they also find that the US women who are working are more likely to work full time and at a higher occupational level than women in other countries. Although the latter analysis does not account for selection into the labour force, which due to the lower labour force participation rate is more stringent in the US and as a result participating women are likely to have better qualifications and ability, the difference is so large that correcting for the stronger selection in the US is unlikely to make much difference. This suggests that the high labour force participation in countries with extensive family-friendly policies may come at the cost of the quality of employment in which women participate.

Despite all these difficulties in designing "good” family policies, when Glass et al. (2016) compare the happiness of parents and non-parents in 22 OECD countries with differing family policies, they find that the difference between parents and non-parents (with parents being less happy than non-parents) is lower for countries with more generous family policies. Paid leave and childcare subsidies are the most important in reducing the difference. The US 
parents, where expenditure on family policies is relatively low, experience the largest "reduction" in happiness when starting a family.

\section{Paid parental leave across the world}

In 2011, when Australia introduced the Paid Parental Leave scheme with near-universal eligibility for employed women, the only developed country remaining without universal paid parental leave was the US. This seemed set to change in the near future with some of the US States (California, New Jersey, Rhode Island) already having introduced a paid parental leave scheme as part of a broader Paid Family Leave program; Hawaii, Puerto Rico and the District of Columbia provide paid leave through the Disability Insurance Program, while New York passed paid family leave legislation in $2016 .{ }^{4}$ Furthermore, Federal introduction of paid parental leave was on the agenda as part of the 2016 presidential election debate in which Hillary Clinton mentioned this as one of her plans. ${ }^{5}$ It was also debated within Congress; however, with the recent election of Donald Trump such plans may be on the backburner again. $^{6}$

In contrast many European countries introduced paid parental leave a long time ago, some going back to the early twentieth century and some unpaid leave even dating back to the late nineteenth century. This section provides an overview of schemes across the world, discussing time of introduction, method of financing, duration and generosity in terms of payment level. ${ }^{7}$ Table 1 provides an overview of paid maternity/parental leave and paid paternity leave, including the year of introducing paid maternity/parental leave.

The International Labour Organization (ILO) (2010) provides an overview for an even more comprehensive list of countries indicating the source of funding. We use the information in Table 1 and the ILO report in the discussion in the following subsections.

\footnotetext{
${ }^{4}$ In Washington, legislation was passed in 2007, but due to a lack of a funding mechanism it has not been implemented yet. Gault et al. (2014) describe the situation in the U.S. and make a case for a universal introduction of paid family leave.

${ }^{5}$ Hillary Clinton Jumps at the Chance to Defend Paid Leave Laws (Huffington Post, $13^{\text {th }}$ October 2015). Bernie Sanders: Every Woman Should Get 12 Weeks Paid Maternity Leave not 2 Weeks Unpaid (The Independent, $8^{\text {th }}$ January 2016).

${ }^{6}$ For details of the proposed Family and Medical Leave Act see https://www.congress.gov/bill/114thcongress/senate-bill/786/text (viewed on 17 January 2017).

${ }^{7}$ For a comparison of 21 countries (including Australia) using a Gender Equality Index see (Ray et al., 2010).
} 
Table 1 Summary of total paid leave entitlements ${ }^{\mathrm{a}}$ available to mothers and total paid leave entitlements ${ }^{b}$ reserved (or effectively reserved) ${ }^{c}$ for fathers (2015 values ${ }^{d}$ )

\begin{tabular}{|c|c|c|c|c|c|c|c|}
\hline & \multirow{2}{*}{$\begin{array}{l}\text { Year } \\
\text { intro- } \\
\text { duced }^{\text {e }}\end{array}$} & \multicolumn{3}{|c|}{$\begin{array}{c}\text { Total paid leave available to } \\
\text { mothers }^{f}\end{array}$} & \multicolumn{3}{|c|}{ Total paid leave reserved for fathers } \\
\hline & & $\begin{array}{l}\text { Length, in } \\
\text { weeks }\end{array}$ & $\begin{array}{l}\text { Average } \\
\text { payment } \\
\text { rate }^{\mathrm{g}}(\%)\end{array}$ & $\begin{array}{l}\text { Full-rate } \\
\text { equivalent, } \\
\text { in weeks }\end{array}$ & $\begin{array}{l}\text { Length, in } \\
\text { weeks }\end{array}$ & $\begin{array}{l}\text { Average } \\
\text { payment } \\
\text { rate }^{\mathrm{d}}(\%)\end{array}$ & $\begin{array}{l}\text { Full-rate } \\
\text { equivalent, } \\
\text { in weeks }\end{array}$ \\
\hline Australia & 2011 & 18.0 & 42.0 & 7.6 & 2.0 & 42.0 & 0.8 \\
\hline Austria & 1957 & 60.0 & 85.3 & 51.2 & 8.7 & 80.0 & 6.9 \\
\hline Belgium & 1954 & 32.3 & 46.4 & 15.0 & 19.3 & 25.8 & 5.0 \\
\hline Canada & 1971 & 52.0 & 52.6 & 27.3 & 0.0 & 0.0 & 0.0 \\
\hline Chile & & 30.0 & 100.0 & 30.0 & 1.0 & 100.0 & 1.0 \\
\hline Czech & & & & & & & \\
\hline Republic & 1956 & 110.0 & 51.1 & 56.3 & 0.0 & 0.0 & 0.0 \\
\hline Denmark & 1933 & 50.0 & 54.1 & 27.0 & 2.0 & 54.1 & 1.1 \\
\hline Estonia & & 166.0 & 51.3 & 85.1 & 2.0 & 100.0 & 2.0 \\
\hline Finland & 1937 & 161.0 & 26.5 & 42.6 & 9.0 & 70.7 & 6.4 \\
\hline France & 1946 & 42.0 & 44.7 & 18.8 & 28.0 & 20.2 & 5.7 \\
\hline Germany & 1911 & 58.0 & 73.4 & 42.6 & 8.7 & 65.0 & 5.7 \\
\hline Greece & 1921 & 43.0 & 53.9 & 23.2 & 0.4 & 100.0 & 0.4 \\
\hline Hungary & 1969 & 160.0 & 44.5 & 71.1 & 1.0 & 100.0 & 1.0 \\
\hline Iceland & 1954 & 26.0 & 63.8 & 16.6 & 13.0 & 63.8 & 8.3 \\
\hline Ireland & 1952 & 26.0 & 35.0 & 9.1 & 0.0 & 0.0 & 0.0 \\
\hline Israel & & 14.0 & 100.0 & 14.0 & 0.0 & 0.0 & 0.0 \\
\hline Italy & 1950 & 47.7 & 52.7 & 25.2 & 0.2 & 100.0 & 0.2 \\
\hline Japan & 1969 & 58.0 & 61.6 & 35.8 & 52.0 & 58.4 & 30.4 \\
\hline Korea & 1987 & 64.9 & 39.0 & 25.3 & 52.6 & 30.7 & 16.1 \\
\hline Luxembourg & 1969 & 42.0 & 62.1 & 26.1 & 26.4 & 39.8 & 10.5 \\
\hline Mexico & 1917 & 12.0 & 100.0 & 12.0 & 1.0 & 100.0 & 1.0 \\
\hline Netherlands & 1966 & 16.0 & 100.0 & 16.0 & 0.4 & 100.0 & 0.4 \\
\hline New Zealand & 2002 & 16.0 & 47.9 & 7.7 & 0.0 & 0.0 & 0.0 \\
\hline Norway & 1977 & 91.0 & 50.0 & 45.5 & 10.0 & 98.7 & 9.9 \\
\hline Poland & 1924 & 52.0 & 80.0 & 41.6 & 2.0 & 100.0 & 2.0 \\
\hline Portugal & 1963 & 30.2 & 66.1 & 20.0 & 21.3 & 54.2 & 11.5 \\
\hline Slovak & & & & & & & \\
\hline Republic & 1956 & 164.0 & 32.0 & 52.5 & 0.0 & 0.0 & 0.0 \\
\hline Slovenia & & 52.1 & 92.9 & 48.4 & 2.1 & 90.0 & 1.9 \\
\hline Spain & 1966 & 16.0 & 100.0 & 16.0 & 2.1 & 100.0 & 2.1 \\
\hline Sweden & 1955 & 60.0 & 63.4 & 38.1 & 10.0 & 75.6 & 7.6 \\
\hline Switzerland & 2005 & 14.0 & 56.8 & 7.9 & 0.0 & 0.0 & 0.0 \\
\hline Turkey & 1936 & 16.0 & 66.0 & 10.6 & 0.0 & 0.0 & 0.0 \\
\hline United & & & & & & & \\
\hline Kingdom & 1948 & 39.0 & 31.3 & 12.2 & 2.0 & 20.6 & 0.4 \\
\hline United States & n.a. & 0.0 & 0.0 & 0.0 & 0.0 & 0.0 & 0.0 \\
\hline OECD averag & & 54.1 & - & - & 8.2 & - & - \\
\hline Bulgaria & & 110.4 & 67.0 & 74.0 & 2.1 & 90.0 & 1.9 \\
\hline Croatia & & 56.0 & 69.4 & 38.9 & 8.7 & 34.2 & 3.0 \\
\hline Cyprus & & 18.0 & 72.0 & 13.0 & 0.0 & 0.0 & 0.0 \\
\hline Latvia & & 94.0 & 57.7 & 54.2 & 1.4 & 80.0 & 1.1 \\
\hline Lithuania & & 62.0 & 100.0 & 62.0 & 4.0 & 100.0 & 4.0 \\
\hline Malta & & 18.0 & 87.1 & 15.7 & 0.2 & 100.0 & 0.2 \\
\hline Romania & & 61.0 & - & - & 1.0 & 100.0 & 1.0 \\
\hline
\end{tabular}


Notes: a) This includes paid maternity, parental and home care leave.

b) This includes paid paternity, parental and home care leave.

c) Information refers to entitlements to paternity leave, 'father quotas' or periods of parental leave that can be used only by the father and cannot be transferred to the mother, and any weeks of sharable leave that must be taken by the father in order for the family to qualify for 'bonus' weeks of parental leave.

d) The table refers to paid leave entitlements in place as of April 2015.

e) This information is collected from the Annex to "PF2.5 Trends in leave entitlements around childbirth" which can be found on the OECD website http://www.oecd.org/els/family/database.htm. Information is not available for all countries.

f) Information refers to parental leave and subsequent periods of paid home care leave to care for young children (sometimes under a different name, for example, “childcare leave” or "child raising leave”, or the "Complément de Libre Choix d'Activité” in France).

g) The "average payment rate" refers to the proportion of previous earnings replaced by the benefit over the length of the paid leave entitlement for a person earning $100 \%$ of average national (2014) earnings. If this covers more than one period of leave at two different payment rates then a weighted average is calculated based on the length of each period. In most countries benefits are calculated on the basis of gross earnings, with the "payment rates" shown reflecting the proportion of gross earnings replaced by the benefit. In Austria, Chile, Germany and Romania, benefits are calculated based on previous net (post income tax and social security contribution) earnings, while in France benefits are calculated based on post-social-security-contribution earnings. Payment rates for these countries reflect the proportion of the appropriate net earnings replaced by the benefit. As a result, the actual amounts received by the individual on leave may differ from those shown in the table.

Source: OECD database (see http://www.oecd.org/els/family/database.htm).

\section{III.1 When was it introduced?}

Table 1 shows that there is substantial variation regarding when paid maternity/parental leave was introduced varying from 1911 for Germany to 2011 for Australia. Not surprisingly several of the early adopters are Nordic countries (e.g. Denmark in 1933, and Finland in 1937) but there are a few unexpected early adopters such as Mexico in 1917, Greece in 1921 and Turkey in $1936 .{ }^{8}$ Norway, on the other hand, only introduced paid leave in 1977 but is now one of the more generous countries with regard to providing paid parental leave.

In most countries, unpaid leave preceded paid leave, often by many decades. In the late 1800s mandatory unpaid leave was introduced in many places, including Austria, Belgium, Denmark, Germany, the Netherlands and Switzerland (the first to adopt unpaid leave in 1877). Italy, Spain and Sweden followed in the very early 1900s. This unpaid leave was mostly intended to protect women's and children's health, and not necessarily so much to advance women's rights. In many cases, the leave did not include job protection. As a result there is not a strong connection between the timing of adopting unpaid leave and paid leave.

\section{III.2 How is it financed?}

Funding sources for each country's maternity leave scheme are reported in ILO (2010). For the countries reported in Table 1 the dominant source of funding is Social Security. That is,

\footnotetext{
${ }^{8}$ For more details see the Annex to "PF2.5 Trends in leave entitlements around childbirth" which can be found on the OECD website http://www.oecd.org/els/family/database.htm
} 
employed workers (and/or their employers) pay social insurance premiums from which maternity leave (amongst other things) is paid. As such, paid maternity leave is clearly a work entitlement in these countries.

Australia and New Zealand are exceptions, as the only two countries where paid maternity leave/parental leave is fully paid by the State from general revenue. It seems that this may be at least part of the reason why paid parental leave is often seen as a welfare payment rather than a work entitlement in Australia. In a few other countries the State pays part of the paid leave: Greece, Iceland and Croatia (remainder paid by Social Security), and the UK (remainder paid by the employer). In two countries, Social Security is combined with funding provided by the employer: Germany and Korea; while in Switzerland Social Security is combined with private insurance, the cost of which is shared between employer and employee. Finally, in Denmark paid leave is funded by local government and the employer, while in Malta paid leave is fully funded by the employer.

The choice of funding is an important one since it will determine the leave scheme's sustainability and support for it in the community. Over the past few years the Australian PPL scheme has regularly been discussed as if it was a welfare payment which is due to the fact it is paid by the Government from general revenue. This has led people to argue against payments for women in high-income households and for payments to women without an employment history. In that regard, funding through social insurance where the premium is raised as a percentage of a person's salary seems ideal as it would avoid this type of confusion by linking paid parental leave to paid employment.

\section{III.3 What is its duration?}

Comparing duration of available paid leave can be complicated since in many countries maternity leave is distinguished from parental leave as the component that is for mothers only, and that is put in place for the health of mother and child before and just after birth. In addition, in more recent years, separate paternity leave policies are provided where part of the leave is required to be taken by the father. In Table 1, the maximum amount of leave that can be taken by the mother (including both paid maternity and parental leave) is presented in the third column, while for fathers we present the amount of leave that can only be taken by the father (i.e. "use it or lose it"). ${ }^{9}$

\footnotetext{
${ }^{9}$ ILO (2010) only presents the length of maternity leave.
} 
With 18 weeks, Australia is clearly at the bottom end of the duration distribution. A few countries have shorter durations (with Mexico at 12 weeks providing the shortest leave), but each of these countries has a higher average payment rate (e.g. 100 percent for Mexico). In terms of full-rate equivalent weeks of leave, Australia is at the bottom (after the US). Most European countries offer at least half a year of leave, with many going up to one year or more of paid leave. All the Nordic countries offer at least 50 weeks of paid leave to mothers. Hungary, Finland, the Slovak Republic and Estonia even offer three years of paid leave, mostly at a relatively low rate, although in terms of full-rate equivalent weeks of leave, Estonia still comes out on top.

Although in recent years, more leave is specifically assigned to fathers, in many countries no leave is assigned to fathers alone, and in several countries the amount of leave is 1 week or less. In this list, Australia is somewhere in the middle at two weeks (introduced in 2013). Luxembourg and France designate just over half a year to fathers while Japan and Korea, perhaps surprisingly, designate one year to fathers. As with the leave provided to mothers, shorter durations tend to be provided at higher replacement rates (mostly 100 percent) while longer durations receive lower replacement rates (between 20.2 and 58.4 percent for the top four in terms of duration of leave).

In terms of full-rate equivalent weeks of leave, about half of all countries listed in Table 1 provide one week or less to fathers, while few countries provide ten weeks or more. Japan and Korea are again at the top of the range with 30.4 and 16.1 in terms of full-rate equivalent weeks of leave respectively.

\section{III.4 How generous is it?}

In this section, the focus is on the average payment rate, although a relatively low average payment rate can of course be compensated by a longer duration of leave. Only a few countries provide a 100 percent replacement of the mother's earnings, and mostly these are the countries that provide short durations of leave (12 to 16 weeks). There are two exceptions to this: Lithuania which provides 62 weeks of leave and Chile which provides 30 weeks. The reverse is true as well, with several of the countries with long durations of leave providing a relatively low replacement rate (e.g. Finland, Slovak Republic, Hungary). Again, there are exceptions here with some countries providing few weeks of paid leave to mothers at a relatively low average rate (e.g. Australia and New Zealand). 
The replacement rate of the father's earnings is 70 percent or more in most of the countries that provide leave targeted to fathers specifically. Mostly this is for short durations of leave, with 10 weeks being the longest leave provided to this group. The countries with low replacement rates (20.2 percent for France is the lowest) typically provide longer leaves. However, again there are exceptions with the UK providing only 2 weeks at a rate of 20.6 percent and Croatia providing 8.7 weeks at 34.2 percent.

\section{Introducing Paid Parental Leave}

A few studies on the impact of paid parental leave are about introducing a paid parental leave policy where before there was none, and which compare the outcomes of people with access to paid parental leave to people without access to paid parental leave.

\section{IV.1 Before and after comparisons}

To evaluate the impact of the Australian universal Paid Parental Leave scheme introduced in 2011, Martin et al. (2015) and Broadway et al. (2016) use data which were collected around the time of introduction. Martin et al. (2015) report on a broad range of outcomes, while Broadway et al. (2016) focus on mothers' labour market outcomes in the first year after birth. The almost universal coverage of the scheme coupled with detailed survey data collected specifically for the evaluation just before and after the introduction of the policy means that eligibility for paid leave under the scheme can be plausibly taken as exogenous following a standard propensity score matching exercise. Consistent with other literature, Broadway et al. find a positive impact on leave taking in the first half year. This is complemented by a higher overall probability of returning to work in the first year. They provide new evidence of a positive impact on continuing in the same job and under the same conditions, where previous conclusions have been mixed. Further, while few studies can distinguish heterogeneous impacts of paid leave, they show that the impact of the PPL scheme in terms of taking leave and returning to work was largest for disadvantaged mothers - low income, less educated, without access to employer-funded leave.

The other studies analysing the introduction of a paid leave policy all relate to the US. RossinSlater et al. (2013) find that leave taking is doubled from about three to six weeks when Paid Family Leave was introduced in California (six weeks at partial pay), with the effect appearing more pronounced for disadvantaged groups (although mostly insignificantly). Between one and three years after birth, paid leave has increased hours worked (and income) 
by 10 to 17 percent. The authors' preferred control group is that of women with a 5 to 17 -year old child. However, the comparison group of women with infants in other states may be more appropriate, despite potential issues regarding differences in economic circumstances (which can be controlled for), since these women will have a similar need (desire) for parental leave unlike the mothers of 5 to 17 year old children. ${ }^{10}$ The estimates based on interstate comparisons result in slightly smaller effects, and in insignificant results for any leave taken (i.e. all leave types combined). Baum and Ruhm (2016) study the impact of the same policy change using different data (the 1997 cohort of the National Longitudinal Survey of Youth) which provide more detail on the leave taking than the snapshot of leave taking observed through the March Current Population Survey (CPS) data from 1999 to 2010 used by RossinSlater et al. Baum and Ruhm's approach involves a multivariate difference in difference analysis using parents from control states without a Paid Family Leave scheme. They find that it increased mothers' and fathers' leave taking significantly by nearly five weeks ${ }^{11}$ and two to three days respectively. For mothers the additional leave taking takes place in the quarter before birth and in the half year after birth, whereas for fathers it is concentrated in the first few weeks after birth. One year after birth women are 18 percentage points more likely to work. In addition, their work hours and weeks worked have increased in the next year.

Examining broader implications for women, Das and Polachek (2015) find an increase in labour force participation and unemployment of the general population of young women in California, using other states as control groups. They suggest that this may be due to the higher cost of hiring young women after Paid Family Leave is introduced, while at the same time employment becomes more attractive to this group. No such effect is found by Waldfogel (1999) for the (unpaid) Family and Medical Leave Act (FMLA), which provides unpaid leave of 12 weeks to a broad group of women. That is, although leave coverage and use increased after FMLA was introduced, it did not negatively affect women’s employment or wages. She used States with prior laws regarding family leave as control groups applying

\footnotetext{
${ }^{10}$ Women with a youngest child aged 5 to 17 are particularly unsuited as a control group when considering the key outcome of being on maternity leave, which is not relevant to these women. The summary statistics show that none of these women were on maternity leave last week, either before or after the policy reform. This is an important shortcoming given that one of the objectives of the control group is to control for any already existing time trends in outcomes, in this case taking maternity leave.

${ }^{11}$ The difference with the result in Rossin-Slater et al. (2013) is due to the fact that Baum and Ruhm can observe leave taking before birth, and their analysis focuses on women who worked at least 20 weeks in the 9-month period before birth rather than all women who worked any amount in the previous calendar year. This latter, broader group used by Rossin-Slater et al. are less likely to qualify for the Paid Family Leave than the more restricted group.
} 
difference-in-difference approaches as well as triple difference approaches using women with older children, women without children, older women and men as control groups. In her wage analysis Waldfogel controlled for any change in the composition of those who were employed. Unpaid leave, in its role of ensuring job continuity with the same employer, reduces the impact of having children on women's wages: i.e. the "family gap” is reduced (Waldfogel, 1998a,b).

Further investigation of the FMLA, focussing on mothers (and to some extent also fathers), leads to mixed results. Goodpaster (2010) finds a negative effect on labour force participation one year after birth from the introduction of FMLA. She suggests this may be due to new mothers learning the value that they place on staying at home with their newborn while they are on leave, and as a result they may decide not to return to the labour force (at least in the short-term). Han and Waldfogel (2003), and Han et al. (2009) find a positive effect on leave taking, which is larger for married mothers and highly educated mothers, who are more likely to be covered by the new law and more likely to be able to afford unpaid leave taking. The effects estimated in Han and Waldfogel (2003) are mixed, with their analysis based on fewer years (from 1991 to 1999, instead of 1988 to 2004) and on taking unpaid leave only. A much smaller effect is observed for fathers than for mothers, with the percentage of time fathers are on leave in the birth month increasing from 7 to 11 percent (with around half of all fathers covered by the leave law) (Han et al., 2009), while Han and Waldfogel (2003) find no effect.

\section{IV.2 Contemporaneous comparisons - controlling for selection}

In a related strand of the literature, a few studies compare contemporaneous women with and without rights to paid parental leave while controlling for the selection into paid parental leave. Before the Australian Government introduced their Paid Parental Leave scheme, some Australian employees had access to paid parental leave through policies provided by their employers. Hanel (2013) finds that the relatively short, paid maternity leave schemes provided by employers in Australia (before universal paid parental leave was introduced by the Government) create an incentive to delay the return to work by a couple of weeks or months, moving the return to work from the first half to the second half of the year after childbirth. No positive or negative effects are found on long-term employment or wages more than a year (and up to four years) after childbirth or on mothers' labour market attachment. Basically the results indicate that short amounts of extra leave can be taken without penalising later labour market outcomes. This result is contrary to Ulker and Guven's (2011) result of earlier return to the labour market for those with paid or unpaid leave eligibility. However, 
although Ulker and Guven control for a broad range of individual, household and employment characteristics when explaining the duration of maternity leave taken, the HILDA data used does not allow Ulker and Guven to control for the possible self-selection of women into jobs providing paid leave, possibly making eligibility for paid leave endogenous.

Burgess et al. (2008) show that UK women with rights to maternity leave return to work earlier than other women (25 percentage points more likely to have returned at seven months), even after controlling for the underlying but unobserved stronger attachment to the labour market of women with rights to leave. They are more likely to return just after four months or just after seven months, points in time that correspond to the duration of paid and unpaid leave respectively. Interestingly, similar to the results for the US (Han et al., 2009), the duration of paid leave is more important for women from low-income households and those without an employed partner, whereas the duration of unpaid leave appears more important for high-skill women with working partners. By eight months, 56 percent of women with rights have returned versus only 12 percent of women without rights.

\section{IV.3 Hypothetical simulation studies}

Finally, there have been a few simulation studies analysing the hypothetical introduction of a paid parental leave policy using previously estimated or calibrated parameters in the context of a dynamic life cycle model. Erosa et al. (2010) develop a general equilibrium model of fertility and labour market decisions, allowing for temporary separations from the labour market to accommodate parents taking leave. The model is calibrated to the pre-FMLA US situation (based on 1988 data) before being used to simulate different leave policies. They conclude that providing paid leave is effective in encouraging mothers to spend time with their newborn children, and that women gain substantially with generous leave policies but that this benefit coincides with a reduction in the welfare of males. However, the way the model is set up implicitly assumes that men (fathers) do not derive utility from leave taken by their partners to care for their children. Similarly, the welfare of children is not taken into account. As a result, positive impacts on child health or child development are not included in the analysis. Ideally a model like this would consider welfare at the family level as partners' choices are likely to affect an individual's wellbeing, and men and women's wellbeing is not independent of each other.

Using a dynamic structural job search model for Austria, Lalive et al. (2014) show that a combination of job protection and paid leave encourages mothers to take some leave after 
childbirth without reducing their labour market attachment in the medium run. Using only one or the other policy does not have the desired effect of achieving the two goals of more leavetaking straight after birth and no decline in medium-run labour market attachment. Low and Sánchez-Marcos (2015) estimate a life cycle model of female labour supply and saving in a household context (where fathers are assumed to always work) which is calibrated to 20042007 US data. Similar to Lalive et al. (2014), they distinguish between a job protection component and an income replacement component of paid leave. They find that job protection leads to substantial increases in short- to medium-run participation of mothers with children under six, and to limited long-run effects. Very small wage effects are estimated: negative selection effects offset reduced human capital depreciation. The income replacement component affects participation and wages to a limited extent. These two simulation studies suggest that paid leave combined with job protection can encourage leave-taking in the first few months after birth while not hurting women's later labour market outcomes. This result is consistent with what is found in studies discussed in the previous two subsections.

\section{Changing the Duration of Paid Parental Leave}

Given the lack of data on changes in duration or generosity of paid parental leave in Australia, the studies in this and the next section are all based on overseas data. Over the past few decades, there have been numerous changes to the duration of paid parental leave in several of the European countries as well as Canada. These changes have been evaluated in a number of studies which show that the duration of payments is an important aspect of paid leave policy.

\section{V.1 Single-country studies}

Germany is one of the countries that has experienced several parental leave reforms, the impacts of which have been extensively evaluated. Between 1979 and 1992, several reforms have occurred: paid leave was first extended from 2 to 6 months, and then from 6 to 10 months, while unpaid leave (i.e. job protection) was extended in three separate steps from 18 to 36 months. Dustmann and Schönberg (2012) find a substantial decrease in mothers' employment from the first two increases in paid leave, mostly in the first year after birth, while the later increases in paid leave had smaller effects mostly on mothers' employment in the second and third year after birth. Schönberg and Ludsteck (2014) analyse these same reforms, which changed job protection and paid leave duration. Although all reforms extending unpaid or paid leave duration reduced short-run labour force participation, only one reform had a substantial longer term impact of more than one month in the first six years. 
When increasing paid leave by 16 months and unpaid leave by four months (in 1986), mothers worked around three months less in the first six years after birth. ${ }^{12}$ German mothers' long-run labour market attachment and income did not improve with the paid and unpaid leave extensions. That is, employment rates, employment income and employer continuity three to six years after birth were only slightly affected by four of the reforms. The exception is again the reform increasing paid leave by 16 months and unpaid leave by four months which extended paid maternity leave beyond the job protected period. This had several negative consequences, harming women's labour market position. Within the first 6 years after childbirth, 4 percent fewer mothers returned to work; mothers' labour market income decreased by 8 percent (with earnings of employed mothers decreasing by about 3 percent); and mothers' cumulative total income, including maternity benefit payments, was nearly DM4,000 lower six years after childbirth, despite an additional expenditure of approximately DM6,000 per mother, on average, on maternity benefit payments.

Germany again changed its parental leave policy substantially in 2007: the duration changed from 24 to 12 months, and payments became more generous and related to previous wage. As anticipated by Spiess and Wrohlich (2008) in their ex-ante analysis, hours worked and labour force participation of new mothers increase in the second year after birth. In a later ex-post analysis of this reform, using a quasi-experimental approach and structural model, Geyer et al. (2015) show that both sets of results indicate less maternal labour supply in year 1 whereas employment increases (modestly) in year 2 after birth across high- and low-income mothers, and across all States in Germany, independent of whether they were part of the former East or West Germany. Simulation with the structural model also considers a childcare reform, which entitles all parents of a child over one year of age to subsidised childcare. This has a large effect on maternal employment in year 2 of almost 5 percentage points. Analysing the same policy change, Kluve and Tamm (2013) find the same result of less maternal labour supply in year 1 whereas employment increases (modestly) in year 2 after birth. The authors suggest that better availability of childcare in States in former East Germany might explain the larger impact of the policy reform on employment in the second year in these States compared to States in former West Germany. The finding that mothers return to the labour market more

\footnotetext{
${ }^{12}$ Strictly speaking, the payments to mothers after 1986 are no longer paid maternity leave since its receipt does not depend on former employment. Only the first two months after birth are linked to former employment and are at full salary. After two months, the payment level is a fixed amount and after six months this fixed amount is income tested on family income two years before birth (which means that women who were employed before childbirth are less likely to receive this payment).
} 
quickly after the reform is confirmed by Bergemann and Riphahn (2015). A decline of 10 months and 8 months for mothers with and without prior eligibility respectively is estimated at the median. The result of increasing labour market attachment of women who were not eligible for paid parental leave before the reform is interesting. The authors find suggestive results that changing social norms, and women's preferences for their own income and economic independence may be driving these results. Newly eligible women would have had no paid leave after the first eight weeks before the reform took place (which is generally thought to be too early to return to work and use childcare), whereas after the reform, paid leave extended until 12 months, making return to work a more feasible and attractive option at the time paid leave finishes. Due to the changes, expenditures on paid leave increased substantially by about 25 percent and more was spent on higher income families after the reform than before the reform when payments were income tested and paid at a low fixed rate.

Paid parental leave in Norway has undergone a number of reforms between 1987 and 1992, increasing its duration from 18 to 35 weeks in several steps. Dahl et al. (2016) analyse these reforms and find that each of the reforms extends the time spent at home with the child with approximately the number of additional weeks of paid leave. That is, hardly any unpaid leave is displaced due to the additional paid leave. However, despite generous payments that ensure that family income is the same for most families in and out of (maternal) employment, the reforms have no effect on the parents' labour market participation, fertility or family stability in the medium to long run. Dahl et al. conclude that these payments are expensive with little effect and come at a high cost both in absolute terms and in terms of redistributing income to high- to middle-income families.

Jacobi et al. (2016) consider the 2000 reform in Austria which increased the period of paid leave from 18 to 30 months. It is clear that this reform extended the amount of maternity leave taken by a substantial amount. They then use the reform to investigate the effect of long (more than 18 months) versus short (less than 18 months) maternity leave on a mother's earnings in the six-year period after her return to paid work. Focusing on the subset of mothers with a strong attachment to the labour market (mothers who return within 30 days of the end of maternity leave and earned over 2980 Euro per year before their leave), they find substantial negative earnings effects from long maternity leave over the first five years after her return. However these negative effects decrease over time: yearly earnings penalties are around 14 to 16 percent in the first year, and decrease to 2 to 3 percent in the fifth year. 
Overall, this results in a considerable cumulative earnings loss over the first five years in the labour market after leave, but it seems that this earnings loss is not permanent.

Unpaid leave in Canada and in some US states has also seen variations in duration. Data for Canada on the changes in statutory job-protected maternity leave entitlements by province between 1976 and 2002 were used by Baker and Milligan (2008) to examine the impact of unpaid maternity leave duration on the period that mothers are away from work post-birth and on the likelihood that they return to their pre-birth employer. Compared to having no leave entitlements, modest leave entitlements of 17 to 18 weeks are shown not to change the amount of time mothers spend away from the labour market, while longer leaves have a substantive impact on behaviour, leading to more time spent at home. All extensions in leave duration increase the job continuity with the pre-birth employer. A similar small impact from providing 12 weeks of unpaid leave (relative to no entitlement to unpaid leave) is found in the US. This provision of unpaid leave has no significant impact on the probability of taking some leave but it increased the amount of leave taken and the proportion of women returning to the jobs they had before childbirth (Baum, 2003a). Berger and Waldfogel (2004) confirm Baum's results and also find that after 12 weeks, the mothers who had access to leave return to work more quickly than mothers who did not have access. Baum (2003b) concludes that the 12-week unpaid leave also has limited (insignificant) effects on wages and employment of women of childbearing age more generally (i.e. not just those that took maternity leave or had children).

\section{V.2 Multi-country studies}

Besides the studies focussing on a specific country and specific reforms to evaluate the impact of changing the duration of paid leave, a number of studies have used data from a number of countries over a period of time to study the impact of different durations of paid leave. Using fixed-effects regressions on aggregate time-series data from 17 OECD countries over four years (1959, 1969, 1979 and 1989), Winegarden and Bracy (1995) conclude that increased duration of paid maternity leave can facilitate some increase in female labour force participation (of the 20-34 age group) without causing decreased fertility. Ruhm (1998) is another early study comparing a number of countries over several years. He finds, based on data for nine European countries (including both Nordic countries and southern European countries) between 1969 to 1993, that paid parental leave increases women's employment rates and that short paid leave has no impact on women's earnings but that longer paid leave eligibility decreases their relative wages. Three months leave are associated with a 3 to 4 
percentage point higher employment rate (with around 1 percentage point being due to paid leave counting as employment) and no change in earnings, while nine months are associated with a 4 percentage point higher employment rate and a decrease in hourly wage by about 3 percent. The increased employment rate is likely to be due to increased pre-birth employment and a quicker return to employment after childbirth, while the lower earnings could be due to human capital depreciation while on (long) leave, employers passing on the costs to female employees, and/or increased female labour supply increasing competition.

In a comprehensive analysis based on 40 years of data (1970-2010) from 30 OECD countries, Thevenon and Solaz (2013) describe the maternity, paternity and parental leave policies that are in place in 2011 and their development over time. Using aggregate data on labour market outcomes, they analyse the impact of the duration of paid leave entitlements. The labour market outcomes considered are: employment rates (available for all countries and years, for men and women aged between 25 and 54), average hours worked per week in the main job (available for 27 countries for varying time periods), and average weekly earnings for fulltime workers (available for 10 countries only, for varying time periods).

Consistent with several micro-economic studies, Thevenon and Solaz find that the availability of paid leave affects female employment rates positively, reducing the gender employment gap. Their results suggest that the effect is more positive when paid leave extends beyond the few weeks usually granted for maternal (and child) health reasons. However, when paid leave is extended beyond two years, female employment rates (and the gender employment gap) are negatively affected. Overall the effects of paid leave on employment rates are quite small; the employment gender gap varies no more than about 2 percentage points in response to the substantial variations in the duration of paid leave. The results also suggest that longer paid leave may allow women to work slightly longer hours on average upon return than when paid leave is not granted. On the downside, conditional on working full time, earnings progression is slower for women than for men when longer paid leave is available thus widening the gender pay gap of full-time employees. It is suggested that women experience slower career and earnings progression on returning from leave to full-time employment, whereas few fulltime employed men take leave. 


\section{Changing the Generosity of Parental Leave Payments}

As discussed earlier, Germany has a history of varying parental leave policies over the past few decades. From 1979 to 1985 paid leave was provided to mothers who worked before childbirth only. In 1986 payments were extended to apply to one parent to stay at home to look after the child (independent of whether this parent worked before the child was born). After the first six months the fixed payment was income tested on annual net household income as it was two years before the birth. As such, it became more like a welfare payment than a work entitlement. As mentioned in the previous section, the German 2007 reform was both a change in duration of leave as well as generosity (through the linkage to previous earnings). The increased generosity ensured that new mothers took up the leave, which reduced maternal labour supply in the first year after birth (Kluve and Tamm, 2013; Geyer et al., 2015). Bergemann and Riphahn (2015) mention the potential importance of providing previously ineligible women with additional paid parental leave between two months and 12 months after childbirth. After two months, return to work by the mother and use of childcare is unlikely to be an attractive and viable option for many families when considering the mother's and child's health and well-being, whereas after one year this option may be feasible and much more attractive. ${ }^{13}$ Having the end of paid leave coincide with the time at which a large proportion of mothers would consider a return to work as an appealing and viable option may provide desirable incentives to return to work by reducing the available income in the "remain on leave" option at this time.

The Nordic countries have a history of well-developed programmes in the areas of parental leave and childcare which have been in place for a very long time, and are thus ideal to study. Pylkkänen and Smith (2003) compare Denmark and Sweden which have family policies that are quite different in design. They examine the leave taking of women after childbirth in the two countries. Sweden has more generous and flexible leave available, while Denmark has more young children aged between 0 and 2 in day care. The authors conclude that women in both countries respond to the economic incentives provided: i.e. they use more non-parental childcare or provide more care at home depending on what is subsidised.

\footnotetext{
${ }^{13}$ The International Labour Organization ratified the Maternity Protection Convention no. 183 in 2000, which recommends a minimum of 14 weeks of paid maternity leave at two-thirds of previous earnings (see http://www.ilo.org/global/standards/subjects-covered-by-international-labour-standards/maternityprotection/lang--en/index.htm ), while the World Health Organisation recommends exclusive breastfeeding for the first 26 weeks (see http://www.who.int/mediacentre/news/statements/2011/breastfeeding_20110115/en// ).
} 
Rønsen and Sundström (2002) also direct their attention to the parental leave and childcare policies of three Nordic countries, Finland, Norway and Sweden. Again, the details of the programmes differed substantially between the three countries (and varied over time) allowing a study of the impact of these details. Data between 1972 and 1992 on women's employment patterns after first and second births is used. Rønsen and Sundström find that being eligible for paid leave increases the probability to re-enter employment after birth, but given that most women use the full amount of leave available to them, this will occur mostly after the leave period has ended. The exception is Sweden where flexibility in taking leave (e.g. deferring some leave until later or taking leave part time) has resulted in more eligible women returning to work before as well as after the leave has been exhausted. When a long leave period is combined with a delay of the return to work until after the leave has been exhausted, it reduces the advantage of eligible women being more likely to return to work by delaying the time at which eligible women return. In Finland the advantage of an increased probability of return to employment experienced by eligible women disappears completely when leave periods extend to over seven months. However, it is suggested that some of this disadvantage may at least be partly compensated by the additional incentive to work more before birth to build up eligibility for paid leave. Increased availability of subsidised childcare increases the probability of returning to work in Norway and Sweden. The home-care allowance system in Finland which subsidises stay at home parents has (unsurprisingly) a negative impact on the return to work.

These analyses show that family policies clearly influence mothers' employment decisions. Too much or too little leave can both negatively affect women's labour market outcomes. "Too much", and women stay out of the labour market longer making a return more difficult (or less “profitable”, e.g. see Blau and Kahn, 2013; or Jacobi et al. 2016). “Too little”, and women are more likely to drop out of the labour force because the end of paid leave does not coincide with the time that women are ready to return to work (Bergemann and Riphahn, 2015).

An interesting paid parental leave option was provided in France for first-time mothers, who (unlike mothers of a second or third child) previously would not have been eligible for paid parental leave after their maternity leave finished ten weeks postpartum. In 2004, six months of paid leave was introduced which could be taken either full time (if the mother does not work) or, similar to the Swedish option, part-time (if the mother works part time). Payment was relatively modest at 552 euros per month (for full leave) to 317 euros per months (if 
working 50 to 80\%). Joseph et al. (2013) analysed the impact comparing post-birth outcomes of mothers exposed to the reform to post-birth outcomes of similar mothers not exposed to the reform. They find somewhat surprisingly that the part-time option (which is particularly popular with high-skilled women) resulted in a significant reduction in subsequent earnings up to two years after childbirth for women exposed to the reform compared to women not exposed to the reform (especially for medium to highly educated women) while the full-time option did not change earnings. A possible explanation for the reduced earnings is that having experienced working part-time, women prefer to continue working part time (rather than full time) after the paid leave period finishes. There is a small positive impact on employment rates from either option with the part-time option having a larger impact particularly for loweducated women.

\section{Paid Paternity Leave}

Leave taking by fathers is still relatively uncommon and if taken, the duration of leave is generally very short and uses other leave rather than designated parental or paternity leave (Whitehouse et al., 2007). Until recently, fathers often had no access to paid parental leave and there is no dedicated leave for fathers. Employment characteristics are important determinants in men's decisions to take parental leave, indicating potential hurdles in the workplace to leave taking by fathers even if the right policies are put in place.

After Australia introduced universal paid parental leave in 2011, two weeks of Dad and Partner Pay (DAPP) was introduced as part of the paid parental leave scheme on 1 January 2013. Martin et al. (2015) evaluate this scheme and find that it facilitated some additional leave taking by fathers (on average one extra day in the first two months after birth). Around 36 percent of eligible fathers used DAPP (those who took DAPP were on leave for 3 days more than those who did not take DAPP). It had the most impact on fathers who were on relatively low earnings (so that the DAPP payment was at a high replacement rate), who had less secure income, or who had no access to employer-paid leave.

Despite the additional one day within the first two months, within the first six months after birth, no extra leave was taken on average. In many cases, the leave taken with DAPP replaced other paid leave that fathers would previously take (mostly annual leave). However, it appears that the introduction of DAPP supported fathers and employers in considering new expectations about men's roles as fathers and how this fits with their work. The qualitative 
analysis reports that some fathers felt the DAPP supported them to insist on their right to take leave after a birth, even if managers, workmates or employers resisted. Similarly, the commencement of DAPP appears to have supported some employers in assisting new fathers to take leave following a birth. Although the concrete impact of DAPP may have been small, its introduction may have assisted in "normalising” taking two weeks of leave around the time of becoming a father.

Bartel et al. (2015) study the impact of the availability of up to six weeks of paid leave at a 55 percent replacement rate (up to a maximum level of \$1,104 per week) for fathers in California (under the same scheme as discussed in Section IV). This increases fathers' leave taking in the first year of their child's life by 0.9 percentage points (a 46 percent increase), while fathers are 50 percent more likely to be taking leave on their own and 28 percent more likely to take leave together with their partners (both increases are from very low starting points). They find that fathers of sons respond more strongly than fathers of daughters, and that the extra leave taken mostly regards first children. They also find that "female-dominated" occupations appear more conducive to leave taking than "male-dominated” occupations.

More generous paternity leave is available in a number of northern European countries. Sweden introduced paid paternity leave in 1995. Ekberg et al. (2013) analyse the impact of this leave. They find that leave is taken (since it is of the "use it or lose it" type providing a strong incentive for take-up), but taking this leave does not change the caring role of fathers later, nor does it lead to better labour market outcomes for mothers. Consistent with this finding, Hegewisch and Gornick (2011:127) note in their review that the egalitarian leave policy in Iceland, where three months each are assigned to the mother and the father, with a further three months to be shared, leads $88 \%$ of fathers to use their component of leave, but the shared entitlement is used mostly by mothers (83\%). Pylkkänen and Smith (2003), in their comparison of Denmark and Sweden, note that Sweden sets more leave aside for fathers. In a policy simulation they find that providing more leave to fathers reduces the mothers' leave taking (and improves her labour supply) in Sweden but not in Denmark. Norway introduced four weeks of exclusive paternity leave (as part of the total of 42 weeks of parental leave) in 1993. Rege and Solli (2013) find a negative effect on fathers' wages which is persistent for at least five years after birth. They suggest this is due to greater involvement of fathers after the initial four-week leave (since otherwise the impact appears too large for what is a very small period of time out of the labour force). However, there is no impact on the mothers' labour 
supply; both parents appear to be more involved at home, increasing overall home production rather than reducing the mother's home production.

The 2007 reform in Germany also involved the introduction of two "daddy" months. From their analysis, Kluve and Tamm (2013) conclude that these two months have not resulted in an increase of fathers' time on childcare yet (at least not within the first 12 months) beyond taking the two months exclusively available to fathers.

\section{Discussion}

This article has described the current situation with regard to paid parental leave in Australia and compared this to a range of other countries. In addition, we have reviewed the literature to learn about the impact of duration and generosity of paid parental leave payments to mothers, as well as the impact of designating a proportion of paid parental leave to fathers.

There are a number of lessons to be learned from the existing literature on paid parental leave that are directly relevant to Australia.

The period of leave cannot be too short, since then women are at risk of exiting the labour force at childbirth rather than having to return to work too quickly, while it can also not be too long, since then women are at risk of losing human capital which is likely to affect their earnings growth and career development. From seven months up to around one year as a maximum appears to be optimal in terms of providing sufficient leave to encourage the health of mother and child (that is, it exceeds the recommended six months by the World Health Organisation) while not being so long that the mother becomes detached from the labour market or suffers a decrease in her human capital. The upper bound of one year is based on evidence from Canada, Germany, Austria and the Scandinavian countries. Although there is some evidence from an aggregate study on 30 countries that leave could be extended to close to two years without adverse effects, given the (recent) evidence on specific reforms in countries such as Germany and Austria, the more conservative upper bound of one year appears appropriate. After one year the risk of human capital loss seems to increase, and return to the labour force at the pre-birth level may be difficult. This means that within the Australian context (where we currently are one of the least generous countries in terms of duration and payment rate of paid parental leave), we are unlikely to be at the stage where further increase in the length of the paid parental leave entitlement would lead to disadvantage women in the labour market. 
Linking the payment level of paid parental leave to previous earnings would encourage women to participate in the labour market and pursue a (well-paid) career before starting a family as this investment is likely to be worthwhile. A high level of payment encourages mothers (parents) to take up paid parental leave. However with the right length of payment period it also induces mothers to return to work when the paid leave period finishes, since the drop in income could be considerable. It is important that the leave stops at the right time, when a large proportion of women would naturally consider returning to work. If it is too early (e.g. two months) then many women would not return to work at that time and the incentive of the drop in income at an opportune point in time is lost (Bergemann and Riphahn, 2015). A high paid parental leave payment could also encourage women to return to work at the previous (high) occupation level between children to gain eligibility at a high payment rate for after the next child is born.

Although it is difficult to achieve a change in behaviour within families, and the caring role of the father appears to adjust only slowly to changing circumstances and incentives, the limited evidence that is available suggests that it may be worthwhile encouraging take-up of parental leave by fathers. Some European countries show that change is occurring, with substantial (and increasing) proportions of fathers actually using the leave that is available to them, with the "use it or lose it" approach being useful in this context. Hegewisch and Gornick (2011) concluded from the research they reviewed that "[men] are much less likely than women to make changes to their employment that might involve a reduction in income.” This may well be a key reason why flow-on effects of early caring roles to later caring roles within the family are still slow to occur.

Finally, observing that in most European countries paid parental leave is funded through social insurance (paid for by all employers, and male and female employees) rather than from general tax revenue (as is the case in Australia), it seems that the funding source may be important in having paid parental leave recognised as a work entitlement rather than a welfare payment. Furthermore, an insurance scheme might make an earnings-dependent paid leave feasible within Australia. This could potentially have an impact on how mothers respond to the paid parental leave scheme. In addition, steering paid parental leave away from the perception of "welfare for middle-class households", this different type of funding might increase population support for a universal paid parental leave scheme in Australia, making such a scheme more sustainable. 


\section{References}

Ainsworth, S. and Cutcher, L. (2008) Expectant Mothers and Absent Fathers: Paid Maternity Leave in Australia. Gender, Work and Organization, 15(4), 375-393.

Baird, M. (2003) Paid maternity leave: The good, the bad, the ugly. Australian Bulletin of Labour, 29(1), 97-109.

Baird, M. (2004) Orientations to Paid Maternity Leave: Understanding the Australian Debate. The Journal of Industrial Relations, 46(3), 259-273.

Baker, M. and Milligan, K. (2008) How does job-protected maternity leave affect mothers' employment? Journal of Labor Economics, 26(4), 655-691.

Bartel, A., Rossin-Slater M., Ruhm, C., Stearns, J. and Waldfogel, J. (2015) Paid Family Leave, Fathers' Leave-Taking, and Leave-Sharing in Dual-Earner Households. IZA Discussion Paper No. 9530.

Baum, C.L. (2003a) The Effect of Maternity Leave Legislations on Mothers’ Labour Supply after Childbirth. Southern Economic Journal, 96(4), 772-799.

Baum, C.L. (2003b) The effect of state maternity leave legislation and the 1993 Family and Medical Leave Act on employment and wages. Labour Economics, 10, 573-596

Baum, C.L. and Ruhm, C.J. (2016) The effects of paid family leave in California on labor market outcomes. Journal of Policy Analysis and Management, 35(2), 334-356.

Bergemann, A. and Riphahn, R. (2015) Maternal Employment Effects of Paid Parental Leave. IZA Discussion Paper 9073, Institute for the Study of Labor, Bonn.

Berger, L. M. and Waldfogel, J. (2004) Maternity Leave and the Employment of New Mothers in the United States. Journal of Population Economics, 17(2), 331-349.

Blau, F.D. and Kahn, L.M. (2013) Female Labor Supply: Why Is the United States Falling Behind? American Economic Review: Papers \& Proceedings, 103(3), 251-256.

Broadway, B., Kalb, G., McVicar, D. and Martin, B. (2016) The Impact of Paid Parental Leave on Labour Supply and Employment Outcomes. Melbourne Institute Working Paper 3/16, University of Melbourne.

Burgess, S., Gregg, P., Propper, C. and Washbrook, E. (2008) Maternity rights and mothers' return to work. Labour Economics, 15, 168-201.

Dahl, G.B., Løken, K.V., Mogstad, M. and Salvanes, K.V. (2016) What is the case for paid maternity leave? Review of Economics and Statistics, 98(4), 655-670.

Das, T. and Polachek, S.W. (2015) Unanticipated Effects of California's Paid Family Leave Program. Contemporary Economic Policy, 33(4), 619-635.

Datta Gupta, N. and Smith, N. (2002) Children and Career Interruptions: The Family Gap in Denmark. Economica, 69(276), 609-629. 
Datta Gupta, N., Smith, N. and Verner, M. (2008) The impact of Nordic countries' family friendly policies on employment, wages, and children. Review of Economics of the Household 6(1), 65-89.

Deven, F. and Moss, P. (2002) Leave arrangements for parents: overview and future outlook. Community, Work \& Family, 5(3), 237-255.

Diamond, C., Baird, M. and Whitehouse, G. (2007) Maternity Leave and Return to Work in Australia - Accessibility and Use in a State Utility. Australian Bulletin of Labour, 33(2), 134157.

Dustmann, C. and Schönberg, U. (2012) Expansions in Maternity Leave Coverage and Children's Long-Term Outcomes. American Economic Journal: Applied Economics, 4(3), 190-224.

Edwards, R. (2006) Maternity Leave and the Evidence for Compensating Wage Differentials in Australia. The Economic Record, 82(258), 281-297.

Ekberg, J., Eriksson, R. and Friebel, G. (2013) Parental leave - A policy evaluation of the Swedish “Daddy-Month” reform. Journal of Public Economics, 97, 131-143.

Erosa, A., Fuster, L. and Restuccia, D. (2010) A general equilibrium analysis of parental leave policies. Review of Economic Dynamics 13(4), 742-758.

Gault, B., Hartmann, H., Hegewisch, A., Milli, J. and Reichlin, L. (2014) Paid Parental Leave in the United States: What the data tell us about access, usage, and economic and health benefits. Institute for Women's Policy Research (IWPR), sponsored by the U.S. Department of Labor Women's Bureau.

Geyer, J. Haan, P. and Wrohlich, K. (2015) The effects of family policy on maternal labor supply: Combining evidence from a structural model and a quasi-experimental approach. Labour Economics, 36, 84-98.

Glass, J., Andersson, M.A. and Simon, R.W. (2016) Parenthood and Happiness: Effects of Work-Family Reconciliation Policies in 22 OECD Countries. American Journal of Sociology, 122(3), 886-929.

Goodpaster, N.K. (2010) Leaves and Leaving: The Family and Medical Leave Act and the Decline in Maternal Labor Force Participation. The B.E. Journal of Economic Analysis \& Policy, 10(1) (Contributions), Article 6.

Han, W.-J. and Waldfogel, J. (2003) Parental Leave: The Impact of Recent Legislation on Parents' Leave Taking. Demography, 40(1), 191-200.

Han, W.-J., Ruhm, C.J. and Waldfogel, J. (2009) Parental Leave Policies and Parents' Employment and Leave-Taking. Journal of Policy Analysis and Management 28(1), 29-54.

Hanel, B. (2013) The Impact of Paid Maternity Leave Rights on Labour Market Outcomes, Economic Record, 89(286), 339-366.

Hegewisch, A. and Gornick, J.C. (2011) The impact of work-family policies on women's employment: a review of research from OECD countries. Community, Work \& Family, 14(2), 119-138. 
Human Rights and Equal Opportunity Commission (2002) A Time to Value: Proposal for a National Paid Maternity Leave Scheme, Available from: http://www.hreoc.gov.au/ sex_discrimination/paid_maternity/pml2/index.html.

International Labour Organization (2010) Maternity at work: a review of national legislation. International Labour Office, Conditions of Work and Employment Branch; Second edition. Geneva: ILO.

Jacobi, L., Wagner, H. and Frühwirth-Schnatter, S. (2016) Bayesian treatment effects models with variable selection for panel outcomes with an application to earnings effects of maternity leave. Journal of Econometrics, 193, 234-250.

Joseph, O., Pailhé, A., Recotillet, I. and Solaz, A. (2013) The economic impact of taking short parental leave: Evaluation of a French reform, Labour Economics 25, C, 63-75.

Kalb, G. and Thoresen, T.O. (2010) A comparison of family policy designs of Australia and Norway using microsimulation models. Review of Economics of the Household, 8 (2), 255287.

Kluve, J. and Tamm, M. (2013) Parental leave regulations, mothers' labor force attachment and fathers' childcare involvement: evidence from a natural experiment. Journal of Population Economics, 26, 983-1005

Lalive, R., Schlosser, A., Steinhauer, A. and Zweimuller. J. (2014) Parental leave and mothers' careers: The relative importance of job protection and cash benefits. Review of Economic Studies, 81(1), 219-265.

Low, H. and Sánchez-Marcos, V. (2015) Female labour market outcomes and the impact of maternity leave policies. IZA Journal of Labor Economics, 4, 14.

Martin, B., Baird, M., Brady, M., Broadway, B., Hewitt, B., Kalb, G., Strazdins, L., Tomaszewski, W., Zadoroznyj, M., Baxter, J., Chen, R., Foley, M., McVicar, D., Whitehouse, G., and Xiang, N. (2015) PPL Evaluation Final Report. Australian Government Department of Social Security, Canberra.

Productivity Commission (2009) Paid Parental Leave: Support for Parents with Newborn Children. Report no. 47, Canberra.

Pylkkänen, E. and Smith, N. (2003) Career Interruptions due to Parental Leave: A Comparative Study of Denmark and Sweden. OECD Social, Employment and Migration Working Papers No. 1, Paris.

Ray, R., Gornick, J.C. and Schmitt, J. (2010) Who cares? Assessing generosity and gender equality in parental leave designs in 21 countries. Journal of European Social Policy, 20(3), 196-216

Renda, J., Baxter, J. and Alexander, M. (2009) Exploring the Work-Family Policies Mothers Say Would Help After the Birth of a Child. Australian Journal of Labour Economics, 12(1), 65-87.

Rege, M. and Solli, I.F. (2013) The Impact of Paternity Leave on Fathers' Future Earnings Demography, 50, 2255-2277. 
Rønsen, M. and Sundström, M. (2002) Family policy and after-birth employment among new mothers - a comparison of Finland, Norway and Sweden, European Journal of Population, 18(2), 121-152.

Rossin-Slater, M., Ruhm, C.J. and Waldfogel. J. (2013) The Effects of California's Paid Family Leave Program on Mothers' Leave-Taking and Subsequent Labor Market Outcomes. Journal of Policy Analysis and Management, 32(2), 224-245.

Ruhm, C.J. (1998) The Economic Consequences of Parental Leave Mandates: Lessons from Europe. The Quarterly Journal of Economics, 113(1), 285-317.

Schönberg, U. and Ludsteck, J. (2014) Expansions in Maternity Leave Coverage and Mothers' Labor Market Outcomes after Childbirth. Journal of Labor Economics, 32(3) (July 2014), 469-505.

Spiess, C.K. and Wrohlich, K. (2008) The Parental Leave Benefit Reform in Germany: Costs and Labour Market Outcomes of Moving towards the Nordic Model. Population Research Policy Review, 27, 575-591.

Thévenon, O. and Solaz, A. (2013) Labour Market Effects of Parental Leave Policies in OECD Countries. OECD Social, Employment and Migration Working Papers, No. 141, OECD Publishing.

Ulker, A. and Guven, C. (2011) Determinants of Maternity Leave Duration in Australia: Evidence from the HILDA Survey. The Economic Record, 87(278), 399-413.

Waldfogel, J. (1998a) The Family Gap for Young Women in the United States and Britain: Can Maternity Leave Make a Difference? Journal of Labor Economics, 16(3), 505-545.

Waldfogel, J. (1998b) Understanding the "Family Gap" in Pay for Women with Children. The Journal of Economic Perspectives, 12(1), 137-156.

Waldfogel, J. (1999) The Impact of the Family and Medical Leave Act. Journal of Policy Analysis and Management, 18(2), 281-302.

Whitehouse, G., Diamond, C. and Baird, M. (2007) Fathers' Use of Leave in Australia. Community, Work and Family 10(4), 387-407.

Whitehouse, G., Hosking, A. and Baird, M. (2008) Returning too soon? Australian mothers' satisfaction with maternity leave duration. Asia Pacific Journal of Human Resources, 46(3), 288-302.

Winegarden, C.R. and Bracy, P.M. (1995) Demographic consequences of maternal leave programs in industrial countries: evidence from fixed-effects models. Southern Economic Journal, 61(4), 1020-1035. 